\title{
LA PALABRA, LA IMAGEN Y EL MUNDO: LAS NOVELAS DE VARGAS LLOSA EN EL CINE
}

\author{
Matías Rebolledo \\ Universidad de Chile \\ majorebo@gmail.com
}

\section{RESUMEN / ABSTRACT}

Uno de los medidores más concretos para dimensionar el impacto cultural y artístico de un autor en estos días es la cantidad de relecturas que generan sus obras (reescrituras, obras de teatro, películas, etc.). Cada una de estas reinterpretaciones genera nuevas perspectivas y lecturas sobre los textos originales, en un diálogo permanente. Al ser Mario Vargas Llosa uno de los autores latinoamericanos más adaptados en cine, se hace importante revisar críticamente las propuestas cinematográficas a partir de su obra. De este modo, este artículo revisa las tres principales adaptaciones de sus novelas, a saber, La ciudad y los perros, Pantaleón y las Visitadoras y La Fiesta del Chivo, analizando algunos aspectos centrales de cada una de éstas, ya sean estructurales o temáticos, para así iluminar algunas dimensiones no solo de cada adaptación en particular, sino de este intercambio discursivo en general.

Palabras Clave: Mario Vargas Llosa, novela, narración, adaptación cinematográfica, intertextualidad.

Nowadays, one of the most concrete ways to measure an author's cultural and artistic impact is the amount of reinterpretations over his works (in literature, theatre, cinema, etc.). Each one of these versions produces new interpretations and perspectives over the original texts, in a constant dialogue. One of the most adapted Latin-American authors to cinema is Mario Vargas Llosa, which reveals the importance of a critical study of the film versions of his works. Thus, this article reviews the three main adaptations of his novels (The Time of the Hero, Captain Pantoja and the Special Service, and The Feast of the Goat) by analyzing central aspects pertaining either to structures or themes in order to elucidate certain dimensions relevant not only to each particular adaptation, but also to this discursive interchange in general.

KEY WORDS: Mario Vargas Llosa, novel, narration, filmic adaptation, intertextuality. 
La experiencia nos muestra que en la mayor parte de los casos en que un autor cinematográfico decide llevar novelas de cierto prestigio al cine, sus intenciones tienen más relación con el impacto social de dichos textos que con la calidad intrínseca o 'potencial fílmico' del texto. Con dicho potencial me refiero a las cualidades que hacen de un texto literario un texto que tiene propiedades estéticas más o menos evidentes, que permitirían no solo la realización de una película en base al texto, sino que con ella se genere un real diálogo entre el objeto original y su versión; en otras palabras, que haya una verdadera potenciación del texto en su realización cinematográfica. Esto, que en gran medida depende de la calidad de la propuesta, hay que considerarlo también desde las características propias del texto: el resultado final está en buena parte predeterminado por el discurso original. De ahí que una buena adaptación dependa en primera instancia de una buena elección. De este modo es válido preguntarse, antes de comenzar un análisis de las transposiciones de las novelas de Vargas Llosa, ¿por qué este autor, y por qué estas novelas y no otras? ${ }^{1} ;$ ¿qué cualidades hacen de estas novelas textos que valga la pena realizar en cine ${ }^{2}$

${ }^{1}$ Las tres películas que se analizarán en este artículo no son las únicas adaptaciones de textos originales del Premio Nobel peruano. Oficialmente se han filmado siete adaptaciones de sus novelas, cinco transposiciones directas, o que pretenden cierta 'fidelidad', y dos versiones más bien libres. La primera de estas películas fue una transposición de su novela corta de 1967, Los cachorros, dirigida por el mexicano Jorge Fons en 1973, y que recibió una buena acogida por parte de la crítica. Luego vendría la versión del propio Vargas Llosa de su novela Pantaleón y las visitadoras (1973), filmada en co-dirección con J. M. Gutiérrez Santos en 1975, aunque oficialmente estrenada en 1980, debido a la prohibición del gobierno peruano. La película no tuvo éxito ni en su corto estreno original ni en su reestreno años después, y hoy se encuentra casi perdida. En 1985 se estrenaría tal vez la más famosa y discutiblemente la mejor lograda película basada en textos de Vargas Llosa, la película homónima sobre la novela de 1962 La ciudad y los perros, del reputado director peruano Francisco J. Lombardi, especialista en transposiciones de textos literarios. La segunda versión de Pantaleón y las visitadoras, evidentemente mejor lograda que la anterior, la dirigiría el mismo Lombardi y fue estrenada con gran éxito de taquilla y crítica en 1999. La última transposición vendría de la mano de un primo de Vargas, Luis Llosa, quien haría una película sobre una de sus últimas novelas hasta esa fecha, La fiesta del Chivo (2000), estrenada en 2005. Para terminar, existen dos versiones algo más libres de sus textos; la primera es Yaguar, del chileno-ruso Sebastián Alarcón, que es una película hecha en Unión Soviética en 1986, basada en La ciudad y los perros. La otra es Tune in tomorrow (Jon Amiel, 1990), un insulto cinematográfico al autor peruano, libremente basado en La tía Julia y el escribidor (1977), que solo menciono para hacer un contexto completo.

${ }^{2}$ La mayor parte de las consideraciones teóricas de este artículo están trabajadas en Rebolledo (9-64). 
Este artículo propone como hipótesis que la relación entre las adaptaciones y las novelas de Vargas Llosa está condicionada por dos elementos centrales. Por una parte, la compleja estructura verbal de las novelas de Vargas Llosa supone una resistencia fundamental para el traslado de medio discursivo. La palabra, en este sentido, se relaciona conflictivamente con la imagen que la sustituye. Por contraparte, el característico realismo del autor (el compromiso de la palabra con el mundo representado) crea un vínculo estético y ético con lo real, que se presenta como un terreno favorable para la transposición, en tanto la imagen cinematográfica se relaciona 'naturalmente' con el mundo que representa. De este modo, la incompatibilidad entre palabra e imagen necesariamente provoca una ruptura con el texto original; dicha ruptura es el lugar del conflicto, pero también el que asegura el rol creativo del realizador. En cambio, la relación palabra-mundo e imagen-mundo explica en gran parte la potencia fílmica de los textos de Vargas Llosa, y que sus textos sean adaptados, pero por otro lado crea una demanda de fidelidad, o al menos un compromiso ético con la propuesta del autor.

Como es sabido, son muchas las motivaciones para llevar un texto a la pantalla, y muchas las maneras de concretarlo; a saber, un realizador puede decidir transponer una obra completa o solo un segmento de ella; puede tomar simplemente un capítulo; puede intentar dar cuenta de todos los personajes, solo de algunos o bien agregar otros; puede hacer lo que se suele llamar una 'versión libre's, etc. De todos modos, hay que considerar siempre que hay algo en el texto que un realizador reconoce y decide desarrollarlo en un medio disímil al original. Por eso, antes que nada, la transposición es un diálogo, un extenso diálogo intercultural, que abarca un intercambio entre los objetos mismos (el texto original y su versión), pero también un diálogo entre los autores, entre el discurso literario en general y el discurso fílmico (o bien, entre el quehacer literario y el quehacer cinematográfico), entre los espacios culturales que enmarcan al texto y posteriormente a la película. Es lo que tradicionalmente se conoce como intertextualidad, pero entendido de manera amplia (como diálogo entre series culturales)(Rebolledo 17-18). Esto es fundamental. Quiero remarcar con este punto que una película viene a modificar siempre de alguna manera a su original: revela dimensiones del texto, crea imaginarios e interpretaciones visuales efectivas, concretas, algo que en la lectura estaba reservado solo al imaginario del lector; establece 
voluntaria o involuntariamente hipótesis de lectura (necesariamente debe cerrar ciertas líneas, abrir nuevos caminos posibles); es, en definitiva, 'una lectura más' de la novela, que se manifiesta en una propuesta estética que, se espera, diga algo más sobre el original. Pero hay más: al divergir el medio se crean condiciones de recepción distintas, se atrae a un público heterogéneo y, normalmente, al superponerse esas condiciones de recepción, se condiciona el sistema de expectativas del público lector ${ }^{4}$ : la novela (su lectura) se modifica con la película, y ésta se modifica con la lectura de aquélla. Incluso, más pragmáticamente aún, el filme puede crear toda una gama nueva de receptores, probablemente muy diferentes a los lectores originales ('prefílmicos') del texto.

Sintetizando, esta relación entre discursos se sostiene fundamentalmente por lo que tradicionalmente se ha llamado adaptación o transposición ${ }^{5}$, que se entiende, en general, como el traslado de una diégesis originalmente literaria (vehiculada a través de la palabra) al medio cinematográfico (que incluye, al menos, una dimensión visual, una auditiva -verbal y no verbal- en una reproducción continua en un tiempo y espacio determinados), una historia (una serie de acontecimientos efectuados por o acontecidos a ciertos personajes dentro de un espacio y tiempo determinados) que se comunica originalmente a través de signos verbales y que, manteniendo sus elementos fundamentales, debe ser trasladada a un medio que utiliza los recursos visuales y sonoros. Como todo cambio de vehículo sígnico, este proceso implica una serie de transformaciones fundamentales, ya que el medio heterogéneo no permite el traslado directo de todos sus elementos. Es precisamente ese espacio de indeterminación el propicio para el diálogo antes mencionado; es el lugar que asegura el lugar del cine como arte autónomo del discurso literario original ${ }^{6}$. Suele ser, también, el lugar propicio para el análisis comparativo.

Ya sea por razones estéticas, o simplemente por el sustrato comercial que siempre requiere el cine, es de esperar que un autor tan importante como Vargas Llosa sea uno de los escritores latinos más adaptados. Aunque

${ }^{4}$ De diversas maneras: en quien no ha leído el texto, creando un imaginario visual del que es muy difícil desprenderse. En quien ha leído el texto previamente, complementando su propio imaginario, contrastándolo, o simplemente negándolo; el caso es que es muy difícil que el visionado no modifique en algo la lectura original.

${ }^{5}$ Definiciones precisas, y operativas para nuestro caso (no se detienen en el detalle de la discusión) vienen en Russo (23), y sobre todo Konigsberg (6).

6 "La literatura ha de ser refundida hasta ser arte cinematográfico. Lo que significa que deja de ser literatura una vez que la película está hecha” (Tarkovski 162). 
ni el éxito ni la calidad están asegurados, basta ver el cine norteamericano y las adaptaciones de casi todos sus textos canónicos para comprender la preferencia por autores consagrados, pese al prurito que le suele producir a la crítica la 'trasgresión' al original en estos textos (de paso perdiendo de vista las cualidades propias del filme). Pero es que el fin de la transposición es siempre recrear, desde la visión particular de un realizador, al menos alguna dimensión del texto literario original, ya sea simplemente la historia o bien elementos de segundo grado, pero siempre transformando su objeto original. De ahí que sea tan importante acercarse cuidadosamente a estos objetos, sin presupuestos que se conviertan en una tara para el análisis.

Bajo este punto de vista, en este artículo intentaré delinear algunas de las principales características formales y temáticas de las novelas estudiadas, con especial detención en aquellos elementos que signifiquen un desafío a la realización, así como aquéllos que permitan pensar en su potencialidad fílmica, confrontándolos a las propuestas concretas en las películas, criticando y evaluando su resultado en tanto diálogos con el texto original. Para sintetizar el análisis, ya demasiado amplio, solo me referiré a algún aspecto central de cada novela, intentando iluminar diferentes aspectos de la problemática.

\section{DE LA NARRATIVA DE VARGAS LLOSA}

Antes de comenzar el análisis específico de las novelas, marcaré algunos aspectos esenciales de la narrativa de este autor ${ }^{7}$, destacando algunas de estas características técnicas y temáticas que pueden agruparse en una serie relativamente continua de elementos, y que crean las condiciones básicas para el análisis de las adaptaciones de sus novelas. Abiertamente confeso seguidor de Flaubert y de la narrativa modernista norteamericana, y sobre todos ellos Faulkner, podemos reconocer un conjunto de características estilísticas y técnicas en las novelas de este autor que se pueden explicar a partir de estas influencias. Éstas, y la del cine ${ }^{8}$. Dichas influencias se expresan de mejor

${ }^{7}$ Algunas de estas ideas están en Goic (276-286) y especialmente Kristal (sobre todo 3-68).

${ }^{8}$ Es importante remarcar que para los mismos autores norteamericanos la influencia del cine fue notable. De hecho, es casi inexplicable la fragmentación y no-linealidad del relato, el multiperspectivismo, la relación entre escena y escena motivada por elementos ajenos a la historia (un sonido, una forma, una palabra), etc., sin, fundamentalmente, la idea de montaje que aporta el cine. A partir del cine, la historia se puede contar en cualquier orden, a partir 
manera en sus primeras novelas; luego, uno podría decir, Vargas continuó este legado, pero encontrando o desarrollando una técnica más personal.

Las tres novelas referidas se caracterizan por un fuerte uso de la técnica narrativa. Aunque cada una a su manera, hay, sin embargo, elementos que claramente comparten; entre estos elementos tal vez el que más las aúna es la perspectiva múltiple de la narración, ya sea a través de distintas voces o a través de un narrador externo que se focaliza en alguno o varios de los personajes. Así, por ejemplo, en La ciudad y los perros (LCP, de aquí en adelante) abundan segmentos en corriente de la conciencia o monólogo interior de los distintos personajes protagónicos, llegando incluso a momentos en que es realmente imposible distinguir el yo que habla. En Pantaleón y las Visitadoras (PV), este multiperspectivismo se manifiesta principalmente, como veremos, en la técnica de diálogo yuxtapuesto que utiliza en varias de sus novelas (más extensamente en Conversación en La Catedral). Además, este cambio de perspectiva va acompañado, en PV, de la multiplicidad de géneros discursivos presentes: parte militar, carta, discurso radiofónico, reportaje periodístico, etc.

De esto último se desprende otra de estas características fundamentales que comparten las tres novelas, que es cómo cada segmento está escrito en un estilo diferente. El ejemplo más claro está, como ya mencioné, en PV, en estos distintos géneros discursivos que al ser enunciados por distintos personajes también evidencian notables marcas estilísticas: desde la parodia del rigor militar en los partes de Pantaleón hasta la retórica popular y sensacionalista del Sinchi, pasando por la narración objetiva 'pura' de los capítulos dialogados con escasas marcas de voz narrativa. Así acontece también con los monólogos interiores, la focalización cero, las narraciones en segunda persona (generalmente, aunque no siempre, en indirecto libre), etc., en las otras dos novelas: cada segmento es una técnica y un estilo diferentes.

De este modo, en estos tres textos se puede decir que se hace uso explícito, evidente, de la técnica del montaje'. Perceptible en un 'estado puro' en LCP, en cuanto es la novela que más claramente y más ostensiblemente recurre a este

de cualquier punto de vista, desde cualquier ángulo, sin que esto signifique necesariamente una historia más confusa. Otros elementos como el encuadre, la perspectiva, etc., también influyeron sobre la literatura.

9 "El montaje supone la fragmentación de la realidad y describe la fase de la constitución de la obra..." (Bürger 137). Esta "fragmentación de la realidad" a través de la técnica del montaje será decidora para el análisis propuesto. 
recurso, es patente también en las otras dos. Además de la técnica específica del montaje, en general las tres novelas hacen explícita la técnica narrativa con que están construidas. Esto es, la técnica no pasa desapercibida, no se esconde: el tema es tan importante como la manera de contarlo (un lugar común en la narrativa contemporánea); estos relatos lo evidencian, hacen gala del espectáculo del lenguaje narrativo ${ }^{10}$. De esta manera, también, se construyen relatos que carecen de una voz narrativa orgánica, que construya un mundo unívoco, estable. A partir del objetivismo de Flaubert, Vargas Llosa concientemente construye historias polifónicas, que desde perspectivas múltiples, a veces incluso contradictorias, deja que ese mundo se muestre en su complejidad, en su ser contradictorio e inestable, evitando narradores que juzguen, comenten u ordenen ese mundo. Esto es sumamente importante para la construcción de los posibles sentidos de sus textos.

Eso en cuanto a la técnica propiamente tal. Ya lo veremos con mayor detalle. En cuanto al estilo o al registro de estos textos, hay otro elemento que considero importante para el cine en la narrativa vargasllosiana. Su apego a un realismo literario (violento, crítico, polifónico) con un fuerte anclaje en la realidad (incluso su propia historia, como en LCP) favorecen este trasvasije medial. Y es que el séptimo arte lleva sobre sus hombros el peso de ser probablemente el medio más realista de representación en el arte ${ }^{11}$. De ahí que, en cambio, hasta hoy no hay ningún filme que sea rescatable de aquéllos que han adaptado a García Márquez, sin importar la calidad de sus textos o el profesionalismo de los directores: su mundo novelesco está demasiado permeado por lo literario (algo similar ocurre con el Quijote). En cambio, las tres películas de este artículo, más allá de sus virtudes o defectos, son películas logradas, objetos autosuficientes, que se sostienen como discurso fílmico; en realidad todas sus novelas son perfectamente 'filmables', más allá

${ }^{10}$ Es posible, eso sí, detectar una cierta 'progresión negativa' en este sentido. De la más fragmentaria y estilísticamente más compleja LCP, hacia una novela un poco más tradicional, con una narración algo más transparente, como La fiesta del Chivo (LFC de aquí en adelante).

${ }^{11}$ Entendiendo que es un discurso icónico que no solo homologa la forma de su referente, como la fotografía, sino que también el tiempo y el movimiento. La identificación del cine con la reproducción mecánica de la realidad lo acompañó desde sus primerísimas proyecciones. De ahí también la fuerte tendencia documental del séptimo arte y las objeciones a su condición artística. Otro aspecto distinto es el contenido propio de las películas; la fantasía es uno de los géneros dilectos del cine-espectáculo, pero en tanto representación, ésta es presentada con una fuerte impresión de realidad. Para este último concepto, ver Metz (17-34); también Mitry (Psicología 97 y ss.). En Casetti (31-54) un resumen crítico de las teorías realistas en el cine. 
de su riqueza técnica, de suyo resistente a un cambio de sostén discursivo (en tanto enfatiza las propiedades ínsitas del lenguaje mismo).

Por último, en relación con las tres novelas que analizaremos, ese mismo realismo toma curiosamente formas similares. Es evidente que, cada una a su manera, las tres son novelas con una fuerte crítica social y política, que se espacializa en un ambiente militar: la educación, en la primera de ellas, la vida (sexual) del ejército en la segunda y, finalmente, la dictadura dominicana en la última de las novelas. El realismo se hace parte de la historia de violencia de América Latina, en diferentes facetas, en diferentes contextos, con distintos tonos, pero siempre rodeados de este ambiente militar. La elección de los realizadores, creo, no es inocente.

\section{NARRACIONES Y SECUENCIAS}

\section{A) Montaje y polifonía de LOS Perros}

Como anunciaba anteriormente, LCP hace un uso ostensivo de los recursos narrativos que utiliza. La forma y la estructura son fundamentales para la constitución del contenido, si nos atenemos a esta separación tradicional. Cada capítulo se divide en numerosos segmentos o secuencias (cinco el capítulo I, seis el segundo, cinco el tercero, etc.), de muy diferente longitud, que utilizan, cada una de ellas, diferentes técnicas y estilos. De esta manera se compone una novela coral (perspectivas múltiples), polifónica (diversas voces narrativas), fragmentaria (historias inconclusas, vacíos, repeticiones, contradicciones), que juega tanto con los tiempos de la historia (los constantes saltos al pasado: los años previos al colegio y los primeros años en éste), como con los tiempos de la narración (largas secuencias para narrar hechos banales, y hechos relevantes, nudos, que se pasan por alto o que no se objetivan nunca, llenando de vacíos la historia). Para el análisis que presentaré bastará con detenernos en el principio de la novela, Primera Parte, capítulo I (1, I). Dicho capítulo presenta cinco secuencias narrativas (para efectos prácticos designadas A, B, C, D, E), que tanto por sus variantes estilísticas como por su desarrollo temático sirve como una especie de obertura de la novela $\mathrm{y}$, por lo tanto, como ejemplo puntual de la estructura novelesca, así como un particular punto de comparación con la película.

La primera frase de la novela (secuencia A) es un diálogo pronunciado por el Jaguar: "Cuatro - dijo el Jaguar" (15). Desde ese punto, que evidentemente 
expresa una situación comunicativa precedente (la incompletitud de las situaciones y la lateralidad de los conflictos son otras de las características de este texto) nos abre el mundo del colegio militar Leoncio Prado desde su acción: el Círculo y su actuar cotidiano. Ningún narrador nos presenta a los personajes ni actualiza al lector sobre la situación que se ha venido desarrollando. Todo se va construyendo en presencia de los dialogantes que, como se verá luego, pretenden robar el examen de química. Solo conocemos los nombres (más bien apodos) de los personajes, y el narrador, que se mantiene bastante distante de los acontecimientos, solo cuenta aquello que tiene que ver con las acciones que se están desarrollando, y no con los antecedentes que nos permiten comprender bien la escena. Los antecedentes que se presentan a través de analepsis ${ }^{12}$ externas no nos dicen demasiado en primera instancia: solo se presenta muy brevemente al serrano Cava ${ }^{13}$ ("Cava había nacido y vivido en la sierra, estaba acostumbrado al invierno", 15) o da algunos datos sobre el colegio ("en años anteriores, el invierno solo llegaba al dormitorio de los cadetes, colándose por los vidrios rotos y las rendijas", 15), que para el grado de conocimiento que tiene el lector en ese punto, aparece como información casi irrelevante. De este modo se desarrolla esta secuencia, entre el diálogo en presente de personajes que aún no conocemos, y un narrador heterodiegético que describe en narración simultánea el robo del examen y entrega las analepsis informativas ya referidas. Información elusiva, intercambio entre diálogos de personajes y la voz de un narrador que solo entrega información parcelada, fragmentaria, y que muchas veces no corresponde a la más relevante para el lector en dicho momento, generando una cierta ambigüedad en los hechos relatados: así se caracteriza uno de los estilos más recurrentes de la novela.

En relación con esa misma ambigüedad, merece especial mención la dificultad para caracterizar el punto de vista de la narración de esta voz, problema que atraviesa toda la novela. Y no es casualidad, pues es claro que Vargas Llosa elude constantemente la figura de una voz unificadora del relato, y así, aun cuando el narrador del caso dé la apariencia de omnisciencia, ésta

12 Los términos técnicos de narratología están tomados de Genette (77-321). Su aplicabilidad al cine está discutida en Rebolledo (42-64) y en el texto de Gaudreault y Jost.

13 Significativamente, en el primer párrafo se le conoce como Porfirio Cava. Nunca más se menciona su nombre, que termina por perderse en las cuatrocientas páginas de la novela bajo el apelativo de "serrano", mucho más decidor que su nombre de pila. El mismo Jaguar, uno de los protagonistas de la novela, nunca es mencionado por su nombre propio. 
se esfuma inmediatamente por marcas textuales que cuestionan su grado de conocimiento. En esta secuencia esto se materializa en un discurso narrativo que a ratos pareciera tener focalización externa, que solo describe aquello que ve y oye, pero rápidamente se elimina dicha posibilidad por la abundancia de referencias internas a Cava, especie de protagonista de esta secuencia ${ }^{14}$, lo que nos lleva a un narrador de focalización interna (y no cero, en la medida en que los pensamientos, sentimientos y conocimiento sobre todo el resto de los personajes es nulo). Sin embargo, esta misma posibilidad se tensiona con frases como "confusamente, deseó perder la voluntad y la imaginación y ejecutar el plan como una máquina ciega" (17), cuya descripción "confusamente" solo podría ser atribuida a un narrador con un conocimiento mayor al del serrano. A la vez, este narrador es esquivo: "Boa y Rulos salieron. Uno de ellos tropezó al cruzar el umbral y maldijo" (16; el subrayado es mío). El narrador no puede ver, no sabe por tanto de quién se habla. O bien, "-Sí -dijo Cava. Su rostro, por lo común impenetrable, parecía fatigado-” (16), que nos presenta una visión puramente externa de Cava. Pero tal vez este comentario sea el que mejor caracteriza a esta voz: "Cava alargó la mano, tocó dos objetos fríos, uno de ellos áspero. Conservó en la mano la linterna, guardó la lima en el bolsillo del sacón" (16); sin transición el narrador pasa de no conocer los objetos a describir qué se hizo con cada uno de éstos, claramente identificados. Es que, como se ve, la dificultad de caracterizar la focalización es porque este narrador rehúye siempre de fijarse. De esta manera, siempre la mirada es un poco esquiva, inasible, aun cuando pareciera haber un discurso ordenador, lo que contribuye notablemente al borramiento de un punto de vista estable, a crear esta fragmentariedad característica, a generar una perspectiva de mundo que nunca es unívoca. Incluso más claro es el ejemplo de la secuencia C, ésta sí claramente focalizada en Alberto, el Poeta: "Alberto ¿ríe? El ruido vibra en la oscuridad como un acceso de eructos, cesa unos instantes, luego brota de nuevo el chorro de desprecio puro, porfiado y sin alegría" (32), donde la mirada pasa, en una frase, de una focalización fuertemente interna, a una focalización externa (o desde la mirada del Esclavo, compañero de escena), que no logra comprender del todo lo que ve u oye, para luego no solo comprender, sino que interpretar el sonido como "el chorro de desprecio puro" sobre Arana.

14 ¿Por qué partir la novela con este 'falso protagonista', que incluso pierde su nombre propio en la novela? 
Como señalé más arriba, esta actitud del narrador básico (o de las instancias narrativas básicas), que transita constantemente desde un adentro a un afuera, que conoce detalles nimios y olvida hechos relevantes, que pasa de un él / ellos a un nosotros sin necesariamente darle la voz explícitamente a nadie, que juega con distintas secuencias temporales, crea esta imposibilidad dentro de la novela de objetivizar y, sobre todo, de uniformizar el relato. De ahí la relevancia de este juego narrativo antes descrito: no es un artificio técnico ni una exquisitez del análisis el detenerse en estos detalles, pues esta manera de contar está en la base de la configuración del mundo presentado. La novela posee un argumento, que no vale la pena resumir acá, lleno de implicancias sociales, políticas, incluso raciales, pero dicho contenido no se sostiene solo. No creo que sea demasiado aventurado señalar que el valor y sentido humano otorgado a los personajes y su historia radica precisamente en esta multiformidad de la experiencia, en la imposibilidad de abarcar la totalidad, en la parcialidad con que cada uno de ellos vive su propia historia, crea su propio mundo inestable, aun cuando comparten ciertas dimensiones de lo real.

Sin necesariamente juzgar el filme, hay que reparar en que esta posibilidad es de plano descartada en su realización. Por una parte, existe la clara limitación que presenta el cine como medio para llevar a cabo una ambiguación del tipo antes descrito. La forma de presentar la imagen es de suyo objetiva ${ }^{15}$, concreta, aun en la llamada "cámara subjetiva"16. De este modo, el tránsito en la focalización de la narración básica, o incluso en las diferentes voces narrativas de los personajes, no es realizable, a priori, con las técnicas elementales cinematográficas. Las implicancias de esta univocidad discursiva resultante quedan explicadas más arriba. De todas maneras, lo que el cine sí puede hacer es limitar el campo perceptual siguiendo a uno o varios personajes ${ }^{17}$, limitando la posibilidad de conocimiento de mundo. Así también

15 En tanto reproducción icónica de su referente, la imagen es concreta, no abstracta ni convencional. Ver, entre otros, Mitry (Psicología 120-121; 152 y ss.); Prince (99-117); Chatman (435-451).

${ }^{16}$ Cámara que intenta imitar la mirada de un personaje. Sin embargo, incluso esta cámara muestra imágenes concretas, y no la percepción subjetiva, mediatizada, selectiva, del personaje, y se delimita por el encuadre, que tampoco corresponde a la mirada 'real'.

17 Este campo perceptual nunca se condice con la percepción real del personaje, en tanto vemos con la cámara, y no a través de su mirada. Así, la focalización en un personaje también incluye, normalmente, al personaje en escena ('vemos ver' al personaje). De ahí que la limitación perceptual corresponde, más bien, convencionalmente, al entorno del personaje en cuestión y no a su actual percepción. 
la fragmentariedad de la experiencia, entendiendo, por supuesto, que los recursos para dicho efecto no se condicen con los literarios. Son todos estos últimos elementos, y no la limitación, si se puede llamar así, del cine en tanto medio, los que quedan descartados por principio en la película de Lombardi. Esto, porque el realizador decide explícitamente convertir en protagonista único de la historia al Poeta y, por lo tanto, casi sin excepción, la limitación perceptual y cognoscitiva del filme se limita a él. El discurso se hace unívoco. Las únicas voces en off que se oyen son las suyas, el conocimiento de mundo que tenemos es el de él. Lo mismo acontece con la temporalidad del relato, que en el filme, a diferencia de la novela, se convierte en un relato lineal, solamente interrumpido por algún pequeño salto temporal (significativamente, una de las primeras escenas de la película, que recuerda el ingreso de los protagonistas al colegio [mins. 3:30 a 8:30 aprox.]; de ahí, nada más).

Veamos ahora el primer segmento de la última secuencia (E), que en tanto estilo narrativo extrema el juego de voces y perspectivas:

"Cava nos dijo: detrás del galpón de los soldados hay gallinas. Mientes, serrano, no es verdad. Juro que las he visto. Así que fuimos después de la comida, dando un rodeo para no pasar por las cuadras y rampando como en campaña. ¿Ves? ¿Ven?, decía el muy maldito, un corral blanco con gallinas de colores, qué más quieren, ¿quieren más? ¿Nos tiramos la negra o la amarilla? La amarilla está más gorda. ¿Qué esperas, huevas? Yo la cojo y me como las alas. Tápale el pico, Boa, como si fuera tan fácil [...] (44)".

En este segmento, donde se nota el paso de una voz colectiva (del Círculo: "Cava nos dijo") a distintas voces narrativas que forman parte de un intercambio dialógico poco definido ${ }^{18}$, se confirma esta complejidad y fragmentariedad de las formas, que en este caso adquiere una tesitura puramente literaria (esto es, verbal). Se trata de una corriente puramente verbal de distintas voces que cuentan de manera semiinconexa la aventura sexual de este grupo con una gallina. Quién narra aquí (digamos, de quién es la voz principal, que convoca al resto de las voces) es, en primera instancia algo confuso. Aparentemente, todos, y nadie. Sin embargo, por marcas que probablemente

18 Esta técnica la desarrollará y complejizará más adelante en su novela Los Cachorros, escrita completamente con este modo de narrar. 
solo se detectarán en una segunda lectura, quién habla es el $\mathrm{Boa}^{19}$, una de las voces narrativas homodiegéticas de la novela (junto a Alberto y el Jaguar). La construcción narrativa aquí demuestra magistralmente, una vez más, un trasvasije entre lo individual (yo, el Boa, su visión bruta y brutal de la vida, su concepción de la violencia y la sexualidad) y lo colectivo (nosotros, los cadetes, nosotros, los del Círculo), que caracteriza este tipo de narración. Pero la secuencia es verbal: el divagar del Boa, los distintos diálogos que se cruzan; hay acción, claro, pero su sustento es demasiado verbal para sustentarse en el cine.

Por último, la secuencia $C$ es la más amplia, tal vez la más característica, por recurrente, de la novela, y la que se sigue más al pie de la letra en la película. Es que, como señalé más arriba, esta secuencia está focalizada en el Poeta, quien se convierte en el solitario protagonista del filme. De hecho, éste comienza precisamente con esta secuencia, para luego introducir la escena de los dados y el robo del examen, con la que comienza la novela. El segmento no está sostenido en la voz del personaje sino por un narrador extradiegético, que cuenta las acciones del Poeta como imaginaria ${ }^{20}$, su encuentro con el Esclavo, cediendo la voz para el diálogo de los personajes, y se cruza también con el divagar mental de Alberto. Ese monólogo interior es restituido en la película (única voz en off audible), solo que nuevamente se presenta una incompatibilidad de medios discursivos, en tanto lo que en la película se oye como monólogo interior que sirve para presentar al personaje, sus recuerdos y sus pensamientos, en el texto original es en realidad corriente de la conciencia, justificada de alguna manera por el divagar mental del personaje que debe 'matar el tiempo':

"y si Huarina hubiera bajado la cabeza, y si me hubiera visto los botines, y si el Jaguar no tiene el examen de Química, y si lo tiene y no quiere fiarme, y si me planto ante la Pies Dorados y le digo soy del Leoncio Prado y es la primera vez que vengo, te traeré buena suerte [...] Y si le robo los cordones a Arróspide, habría que ser desgraciado para fregar a un miraflorino habiendo en la sección tantos serranos que se pasan el año encerrados como si tuvieran miedo a la calle, y

19 Es el único que recibe apelación directa; no aparece ninguna marca del tipo "dijo el Boa”, como sí se refiere al resto del grupo. Siendo la voz colectiva del Círculo, la voz principal solo puede pertenecer a alguien de este grupo.

${ }^{20}$ Turno nocturno de guardia. 
a lo mejor tienen, busquemos otro. Y si le robo a alguno del Círculo, a Rulos o al bruto del Boa, pero y el examen, no sea que me jalen en Química otra vez. Y si al Esclavo, qué gracia, eso le dije a Vallano y es verdad, te creerías muy valiente si le pegaras a un muerto, salvo que estés desesperado. En los ojos se le vio que es un cobarde como todos los negros, qué ojos, qué pánico, qué saltos [...] El Esclavo necesita que le saquen el miedo a golpes, le robaré los cordones a Vallano" (28-29).

En este fragmento vemos una sucesión no muy motivada de hechos potenciales, conectados por el reiterativo "y si"; no se trata, entonces, de una voz narrativa informativa, sino de la sucesión relativamente caótica de pensamientos del personaje. Más aun, tal como señalé, este capítulo funciona como una especie de obertura de la novela, tanto en sus formas de narrar (todas estas secuencias son ejemplares para los capítulos subsiguientes ${ }^{21}$ ), como en los temas y contenidos. Pues bien, este breve fragmento es quizá uno de los mejores ejemplos en este sentido; de ahí la importancia de este divagar del Poeta: ahí están presentadas la vida al interior del colegio (la ley del más vivo -los robos-, del más fuerte -el Esclavo y los abusos-), el conflicto que desencadena los hechos de la línea argumental central (el robo del examen), el microcosmos peruano del colegio, con sus problemas raciales (Vallano, el serrano) y sociales (el miraflorino venido a menos), y la vida sexual de los cadetes (la Pies Dorados). Todos los temas centrales, tanto de la diégesis misma como las relaciones extraliterarias que se pueden establecer, están condensados en este capítulo; nuevamente vemos la maestría con la que se pasa de lo absolutamente subjetivo e individual (la corriente de la conciencia) a lo colectivo y social. Vemos, otra vez, la densidad constitutiva de cada frase; otra vez la importancia de la forma narrativa.

Al relacionar estas primeras secuencias con lo que ocurre en el filme, podemos apreciar la disposición general que organiza la puesta en escena del realizador peruano. Hemos visto que la película parte con la secuencia $\mathrm{C}$, transformando lo que era corriente de la conciencia en la novela en breves monólogos interiores de Alberto, más bien informativos; tenemos luego la analepsis que nos introduce de lleno en el ambiente violento y deshumanizador

${ }^{21}$ De hecho, ejemplares para las obras por venir de Vargas Llosa (Perera 817-824). 
del colegio militar y nos presenta al personaje del Jaguar ${ }^{22}$, para luego continuar con la secuencia A, el robo del examen (que podemos suponer temporalmente paralela a la secuencia $\mathrm{C}$ ), y continuar con un relato lineal, clásico, que concentra la historia en los acontecimientos ocurridos dentro del colegio. De esta manera, en la base de este nuevo relato se encuentran dos transformaciones fundamentales, a saber, una primera transformación obvia, que va implicada en cualquier cambio de medio narrativo, que consiste en adaptar las formas a las exigencias y recursos del nuevo tipo de discurso. No solo significa acá transformar el discurso verbal en imágenes (que a su vez supone una serie de interpretaciones y elecciones de base), sino completar en estas mismas todo aquello que no estaba en el discurso original, para satisfacer la necesidad de completitud visual del medio cinematográfico. La segunda transformación fundamental corresponde a una decisión autorial, que convierte la complejidad de las estructuras narrativas de la novela en un relato lineal, que prefiere la simplicidad estructural y que se adapta de pleno a la forma del relato cinematográfico clásico, esto es, una forma narrativa que privilegia la claridad en la comunicación de la historia, la secuencialidad del relato, y que busca ocultar las marcas de enunciación (el encuadre, los movimientos de la cámara, el montaje, etc. ${ }^{23}$. De este modo, en cuanto a la forma del relato propiamente tal, la película adopta una actitud que se encuentra en las antípodas de la propuesta de Vargas Llosa.

Podemos señalar, entonces, que el principio estructurante de La ciudad y los perros, la película, es su claridad narrativa. Siendo esto así, habría que analizar qué elementos de la novela toma Lomabardi para su realización, en tanto la forma novelesca queda descartada, y es claro que su filme tiene algo que decir, más allá de la reproducción del texto. Para entender esto también debemos reparar en otra de las decisiones autoriales del filme: la acción se reduce, casi en su totalidad, al acontecer dentro del colegio, eliminando, de este modo, largas secuencias que ocurren en la ciudad de Lima, y que en general tienen que ver con los antecedentes biográficos de los personajes (particularmente de Ricardo Arana, Alberto Fernández y el Jaguar). La

${ }^{22}$ Única analepsis visual de la película (hay, evidentemente, rememoraciones verbales); analepsis que, dicho sea de paso, sirve más para justificar el título de la novela ("los perros") que como información necesaria para el desarrollo de la diégesis.

${ }^{23}$ Si hay narración en cine, ésta tiende a borrar sus huellas, sobre todo en el cine tradicional (Rebolledo 50-55; Gaudreault y Jost 47-70); para algunos autores lo que se elimina es la elocución (Mitry, Semiología 109-114). 
secuencia D de este primer capítulo, de hecho, corresponde a un segmento puramente descriptivo ${ }^{24}$, solo interrumpido hacia el final por un breve diálogo, que corresponde a la llegada de Alberto (todavía no era el Poeta) a la avenida Diego Ferré, en Miraflores, cuando aún era un 'niño bien'. Todas estas descripciones espaciales, así como las acciones que acontecen fuera del mundo del colegio, van configurando el perfil psicológico y sobre todo social de los personajes reunidos en el microcosmos del Leoncio Prado. El núcleo urbano convocante que es la institución se desparrama sobre la ciudad a través de las esferas sociales (y raciales) que representan los cadetes. La ciudad se hace presente en ellos.

En cambio, los pocos acontecimientos de la película que aparecen fuera de la institución corresponden todos al presente, y tienen relación directa con la línea argumental seguida en la película (la relación con Teresa, la acusación en casa del teniente Gamboa). La ciudad desaparece del filme. De ahí que su título es más bien una marca de fidelidad al texto que le sirve de base, y escasamente se refiere al desarrollo real del filme, que, tal como se presenta, no explica realmente su título ${ }^{25}$. Por eso es que aquella escena del principio de la película, que rememora la llegada de los cadetes (los perros) al colegio aparece como algo espuria: es el único flashback de la película, aparentemente no está motivado por nada, y no agrega realmente ninguna información trascendental para el desarrollo posterior de la diégesis. Así, con la ciudad ausente del relato, falta aún la segunda parte del título: queda explicada en una de las primeras escenas; luego, los 'perros' dejan de ser parte de ese mundo diegético.

Restaría, entonces, comprender mejor algunas de estas decisiones y revisar lo que implica esta propuesta cinematográfica. En síntesis: primero, el cambio formal de la narración, que transforma un relato complejo, multiforme, que hace gala de su técnica narrativa, que necesita de ella para el despliegue de mundo que se presenta, en un relato lineal, austero, de corte clásico, que esconde sus marcas de enunciación. Segundo, relacionado con lo mismo, la supresión de la multifocalidad y la pluralidad de voces por un relato con

24 "La calle Diego Ferré tiene menos de trescientos metros de largo y cualquier caminante desprevenido la tomaría por un callejón sin salida..." (39).

${ }^{25}$ Desde este punto de vista, tal vez sería más representativo para la película el título que lleva la novela en su traducción al inglés, The Time of the Hero (ya que el filme tiene su propio héroe) que, a su vez, no parece un título muy pertinente para el texto. 
un protagonista único, y por lo tanto en un relato monológico. Tercero, la reducción de las líneas diegéticas a la línea única del presente narrativo, omitiendo todo elemento previo (las historias de los personajes) o externo al colegio, dejando de lado cerca de la mitad de la novela. Son estos tres puntos centrales en los que me he detenido. Vamos por parte.

En cuanto al primer y segundo punto, hay que ponerlos en relación con el mensaje que se quiere comunicar, y el público receptor al que está destinado. El público cinematográfico es tradicionalmente mucho más conservador que el público que lee. Las expectativas están fuertemente condicionadas por el circuito canónico que ha generado el cine norteamericano; en realidad, cuando nos referimos a un 'relato clásico', nos referimos siempre al modelo creado en Hollywood entre los años 30 y 50. El cine de 'arte y ensayo' siempre ha llegado a un número relativamente insignificante de público, algo insostenible para un cine de producción menor, como el latinoamericano. Así, la película espera llegar a un público amplio, no a una pequeña elite. Pero, además, es claro que el eje de esta trasposición es fundamentalmente temático, lo que significa la concentración en la crítica política, social, educacional, e incluso histórica. Son los hechos, no las dimensiones internas que adquieren esos hechos en la novela, ni la conformación de un mundo inestable o fragmentario lo que le interesa al autor, sino la exposición, violenta y crítica, de una historia cuyas implicancias tienden más hacia la visión política de una imagen país, que carga con un sino de violencia y brutalidad, detrás de falsos valores asociados a la educación, a la hombría, a las relaciones humanas, a los principios morales. La claridad de la forma se pone al servicio de dicha denuncia.

La elección del Poeta como foco narrativo y héroe único de esta cinta, limitando la participación del resto de los personajes a sus relaciones directas o indirectas con él, significa proponer un discurso homogéneo y monológico, pero para el receptor actúa como un personaje guía con el cual puede identificarse, puede seguir su proceso de aprendizaje, su caída de golpe en la realidad. Siguiendo la idea trazada en el párrafo anterior, el receptor va adquiriendo su conocimiento de mundo de la mano con Alberto, en presente, chocando con las mismas barreras, cayendo en cuenta junto con él. La mirada se personaliza, pero de esta manera se universaliza: crea la posible identificación del receptor.

Por último, en cuanto a la 'desaparición' de la ciudad como núcleo de sentido del filme, obviaré el problema práctico de las limitaciones temporales y presupuestarias de la realización (la película dura 144 minutos, ya muy cargados de información, aun eliminando cerca de media novela), y me fijaré 
en lo que esto supone como resultado. El choque y la crítica de valores son el centro de esta versión, no el trasfondo psicológico que hay detrás, tampoco se concentra en la idea de la precariedad del mundo establecido y, si bien seguimos el camino del Poeta, la narración es imparcial, distante, y por lo tanto evita la subjetividad de las miradas. El relato se objetiviza. Desde este punto de vista, la ciudad discursivamente 'sobra', el mundo fuera de la escuela no es lo esencial, tampoco los antecedentes previos de los personajes. La historia se sostiene y desarrolla en el microcosmos del colegio, se concentra en ese universo cerrado que, como (posible) alegoría de una imagen país, insiste en su espacialidad agobiante (a ratos la imagen se vuelve claustrofóbica), en la imposible salida (solo se puede salir degradado, como el serrano, o muerto, como Arana), en la tensión de fuerzas en pugna, en la radicalización, producto del encierro, de los valores antes descritos; en, finalmente, una jerarquía y burocracia casi kafkianas, insoslayables. El gris, el verde musgo, el café opaco, son los colores que tiñen la película, potenciando elementos que ya estaban contenidos en la novela, pero concentrándolos como única línea discursiva.

\section{B) La exuberancia de la Colombiana}

Me he detenido tal vez algo más de lo necesario en el análisis de LCP, en tanto las características de esta novela, sobre todo por su estructura narrativa, sirven como paradigma de lo que acontece en el resto de sus textos. De alguna manera, el posterior desarrollo novelístico de este autor se encuentra ya prefigurado en este texto inicial y, por lo tanto, los elementos que hemos revisado anteriormente caracterizan, en parte, lo que acontece en los dos siguientes textos. Es por esto que el análisis de las dos novelas que siguen será algo más breve, rescatando solo algunos elementos centrales y específicos.

Más allá del tema que se desarrolla en Pantaleón y las Visitadoras, y el gran manejo del humor y la ironía que caracterizan a esta novela solo en apariencia trivial, es un texto que en su forma se manifiesta como altamente complejo. Es una novela técnica, si se puede decir. En el caso de esta novela, lo que más llama la atención es la proliferación discursiva, en tanto relato constituido de pequeños fragmentos de diversos géneros discursivos. Cuatro capítulos completos están escritos en puro diálogo, donde se yuxtaponen conversaciones en distintos lugares y tiempos, sin que se pierda la continuidad narrativa. Del resto, claramente el género que mayor presencia tiene es el parte militar, en particular aquellos de Pantaleón, abundantes en la retórica institucional (el gesto irónico y humorístico proviene precisamente de esto: 
un estilo que no se condice con el tema sobre el que trata el discurso). No está de más señalar que hay partes con diversas autorías, además de otros tipos de discursos militares similares, como las "Resoluciones", "Informes" y "Disposiciones internas". Además aparecen cartas, el discurso radiofónico de "La voz del Sinchi", instructivos, crónica periodística y relatos de los sueños de Pantaleón. De este modo, en tanto estructura, estamos nuevamente ante una novela de alta complejidad, solo que, esta vez, con un discurso que no es nunca elusivo o esquivo, sino todo lo contrario: la historia gana en agilidad, continuidad, y sobre todo riqueza estilística, que también es una de las formas más evidentes de manejar los recursos humorísticos de la novela.

Pese a que el cine no se sostiene en el discurso verbal, Lombardi intenta incorporar algunos de estos elementos textuales en su película, no pensando en emular la estructura de la novela, sino que rescatando, dentro de lo posible, algunas de las riquezas discursivas que esta forma tiene. Así, los partes de Pantaleón son enunciados por él en off, mientras sus superiores lo leen: no puede perderse uno de los recursos básicos del humor en el texto. También se aprovecha, en una excelente caracterización, los discursos radiales del Sinchi (de hecho, aquí la película 'recupera' la forma oral original de ese discurso, que Vargas Llosa debe 'sustituir' por su forma escrita). La elegía de Pantoja a la Brasileña / Colombiana es, por supuesto, vista en pantalla. Todos estos elementos no tienen el mismo sentido que tenían en el texto, pero esto no significa una pérdida sustantiva, pues la fluidez y agilidad de la novela logran un buen desarrollo en la película, y dichos elementos son rescatados de manera pertinente para potenciar en pantalla algunas de las riquezas textuales, vale decir, el humor, muy bien logrado en la película, la caracterización y representación visual y social de los personajes. En relación con este punto queda por decir que una vez más, frente a una novela que supone una proliferación de recursos narrativos, nos encontramos con una película, ésta incluso más que la anterior, con una estructura sumamente clásica, de una gran sobriedad formal (la exuberancia está dada por el tema, no por su puesta en escena). Características ya evidentes del cine de Francisco J. Lombardi.

Siguiendo este comentario último, esta vez me detendré en el nivel diegético, y no narrativo o estructural de la transposición. Como en toda transposición, hay una serie de elementos de la historia que deben ser suprimidos, adaptados o interpretados. Los de este filme son varios; menciono solo los principales: la historia, situada en los años 50 se actualiza; toda la línea de la diégesis relacionada con los Hermanos del Arca se suprime; no existe la madre de 
Pantaleón, etc. Sin embargo, es claro que la transformación fundamental es el nuevo protagonismo adquirido por la Colombiana, que no solo cambia de apodo (por la Brasileña), lo que resulta solo anecdótico, sino que adquiere un rol muy distinto en la versión fílmica.

En la novela de Vargas Llosa, la Brasileña apenas es mencionada hacia la mitad del texto, y toma un rol relativamente protagónico pasada la mitad ${ }^{26}$. En la medida en que este personaje, además, no tiene voz narrativa (solo aparecen sus palabras en los capítulos dialogados), su participación es tratada de manera lateral. Su historia con Pantaleón Pantoja es relevante, pero de ningún modo podríamos decir que es la línea argumental central de la novela. En cambio, en la película casi inmediatamente se introduce al personaje [min. 16, aprox.], y rápidamente se convierte en protagonista. Si hay un coprotagonista en la película, esa es la Colombiana. De esta manera opera una transformación fundamental que implica un cambio de género en la película, pues el centro articulador de toda la historia y todas sus ramificaciones se desplaza desde la paródica vida militar en el servicio de visitadoras, con el contrapunto temático de los Hermanos del Arca, a la relación amorosa entre los dos protagonistas. El eje romántico, del amor imposible, sumado en este caso a un ambiente inverosímil, conecta a esta película con quizá la más larga tradición genérica cinematográfica. Un conflicto, sea cual fuere éste, que va acompañado de una historia de amor como correlato de dicho conflicto, es la base del relato modélico cinematográfico ${ }^{27}$.

${ }^{26}$ Es mencionada por primera vez en la página 114 ("El sequeto es la Brasileña [...] Te lo julo, Chuchupe. La conoció anoche [...] y quedó bizco"), pero aparece en escena solo hasta la p. 129. El capítulo 9 y penúltimo (247-276) está dedicado a su muerte. Cinco capítulos de diez.

27 Así define el relato ‘tipo' clásico el teórico norteamericano David Bordwell, establecido en la práctica en Hollywood entre las décadas de los 30 y los 50, y que, variantes incluidas, ha servido de patrón a la gran mayoría de los filmes hasta hoy: "Habitualmente, el argumento clásico presenta una estructura causal doble, dos líneas argumentales: una que implica un romance heterosexual, y otra que implica otra esfera (trabajo, guerra, una misión o búsqueda, otras relaciones personales). Cada línea tiene un objetivo, obstáculos y un clímax [...] En la mayoría de los casos, la esfera del romance y la otra esfera de acción son distintas pero interdependientes $[\ldots]$ frecuentemente las dos líneas coinciden en el clímax: resolver una provoca la resolución de la otra" (157-158). Si a esto le sumamos individuos sicológicamente definidos, que luchan por resolver un problema claramente identificado o por objetivos específicos, que en el transcurso encuentran fuerzas opuestas y termina con un desenlace claro, Pantaleón y las Visitadoras es prototípica del modelo narrativo propuesto por el autor. 
Este cambio fundamental, como mencioné, transforma esta gran parodia de Vargas Llosa en un filme de género. El gran problema del choque valórico entre Pantaleón, el ejército y la máscara hipócrita de la sociedad termina por desplazarse a un segundo plano (no es que desaparezca) en pos de una película que pone en escena un amor imposible en un espacio poco habitual. Casi las únicas escenas inventadas del filme corresponden a esta relación; son también las escenas más detenidas y las más decisivas. El registro también se transforma: la sexualidad paródica de la novela (los nombres, las estadísticas, las situaciones) y gran parte de la película, se convierte, en las escenas de los coprotagonistas, en un erotismo íntimo, y en ningún caso cómico. Visto desde este punto de vista, el verdadero conflicto de la película se resuelve, para bien o para mal, con la muerte de la mujer (tal vez el único final posible); en la novela, dicha muerte es la gatillante del desenlace ${ }^{28}$, no el desenlace en sí.

Ahora bien, esto no debe sonar a priori como un juicio valorativo ("la película se reduce a un esquema prototípico del cine comercial”), pues hay que estimar, primero, que la cinta reconoce la necesidad de un dinamismo y una agilidad de un relato que no se genera, ni puede, bajo los mismos recursos que la novela. Segundo, es evidente que está pensada para el gran público, que reconoce en el cine otros modelos que los literarios. Tercero, la película, por sobre todas las cosas, logra una gran caracterización de los personajes (especialmente la Colombiana y el Sinchi), que se convierte en un atractivo visual en sí mismo, y un gran logro como adaptación: el valor social de la novela hace eco en la película gracias a esto. Finalmente, mediante todos los recursos antes señalados y con todas las transformaciones requeridas, un logro fundamental de la película es conservar el gran sentido del humor de la novela, sin trivializarlo (por ello no es pertinente el juicio valórico ante la estandarización del relato) y preservando en parte su sentido crítico. Es por lo mismo que, aun con los cambios estructurales y sobre todo con los cambios en la diégesis que implican un cambio de estilo y de género (comedia romántica), es un filme muy bien logrado, valorable por sí mismo. De este

${ }^{28}$ La desaparición de la institución de las visitadoras y la reordenación del mundo, el statu quo inicial, con el cierre circular del texto ("Despierta, Pantita"). Pero esta reordenación es también una ironía (las máscaras se develan): ahora es el mismo alto mando, que condenó a Pantoja, el que disfruta exclusivamente de las 'prestaciones' de las visitadoras, y Pantaleón, en su castigo en la puna, vuelve a tomar la rutina obsesiva del trabajo perfecto. Por otra parte, este fanatismo de Pantaleón pierde en la película su contrapunto en la novela: el fanatismo del Hermano Francisco. 
modo, pese a la extrema simplificación del texto, se puede decir que en este diálogo intertextual la película aporta una gran riqueza visual, la encarnación de tipos sociales muy bien logrados, y logra transformar los mecanismos del humor literario en humor fílmico. Podríamos decir, por último, que en un estilo que caracteriza al director (la simpleza y claridad de las formas), y no al autor del texto, la película carga un poco la balanza ${ }^{29}$ hacia uno de los aspectos que estaba en la novela, potenciándolo, enriqueciéndolo, creando un discurso complementario al de la novela.

\section{c) La historia 'verdadera’ Del Chivo}

La Fiesta del Chivo es una novela histórica que ficcionaliza los últimos años de la dictadura de Trujillo, a partir de los cuales, además, intenta dilucidar los procesos que llevaron a la consagración de esta dictadura de carácter casi mítico. Nuevamente la perspectiva narrativa es sumamente relevante, pues está estructurada en torno a tres líneas centrales: la primera que muestra los últimos momentos de la vida del dictador, desde su punto de vista o siguiendo a alguno de sus cercanos; la segunda línea es la del grupo que iría a matar a Trujillo, que incluye las analepsis focalizadas en cada uno de ellos, que completan la información para entender cómo han llegado a tal situación; la tercera línea es la del regreso de Urania Cabral a Santo Domingo, luego de treinta y cinco años, y la recuperación de su pasado. Las tres líneas se van alternando en capítulos más o menos equivalentes.

Estamos ante una novela polifónica, que a través de su multiperspectivismo va creando un vasto espectro de una época y una figura compleja. No posee las mismas cualidades estilísticas ni técnicas que las novelas anteriores, pero de todas maneras es un relato que juega con las diferentes focalizaciones, con los distintos tiempos y, en menor medida, con las distintas voces del relato. Cabe mencionar que de las tres películas trabajadas, solo ésta intenta, a través del montaje, reproducir estas distintas instancias de la narración, especialmente los saltos temporales. La secuencia de escenas está bien construida, y tal vez sea lo mejor que presenta la película con relación al texto. La película homónima dirigida por Luis Llosa es una película que, en cuanto a factura (producción, fotografía, montaje, etc.), parece ser de mejor calidad que las anteriores. Sin embargo, hay que ver qué significa realmente dicha calidad.

${ }^{29}$ Es probable que un lector común ni siquiera note demasiado este cambio de énfasis. 
Más allá de la estructuración y la forma de narrar, que en parte han sido analizados a través de las dos películas anteriores (en este sentido, LFC es bastante menos compleja y, por lo tanto, menos problemática), quiero detenerme en otro aspecto de este texto, que no ha sido trabajado con los anteriores. En tanto novela histórica, gran parte de su fuerza, de su relevancia estética y social, radican en esta recreación de un mundo 'real', de la más reciente historia de Latinoamérica. Vargas Llosa no tiene problemas no solo en darle voz al tirano, sino que prestarle la voz narrativa a personajes envueltos en esa historia que aún están vivos en el momento de publicación de la novela (como Balaguer). La agilidad del relato, la fuerza representativa, el lúcido juego de miradas, y sobre todo la verosimilitud con que se construye esta novela, son elementos vitales para su resultado. Es un tema complejo, y compleja es la manera de resolverlo. La imbricación entre hechos y personajes reales (como es toda la secuencia del asesinato de Trujillo) con elementos ficcionales que dan cuerpo a esta historia (la protagonista, Urania) debe darse de tal manera que lo verosímil reciba la fuerza de lo verdadero, $y$, de esta manera, que el regreso de Urania a su país a reencontrarse con su historia sea una mirada que atrape al lector como una posible mirada, verosímil, sobre lo real. A partir de esta apreciación (discutible, por lo demás) revisaremos este aspecto central de la construcción novelesca en este texto, revisando el último capítulo de la novela, y su comparación con la propuesta del filme.

La escena representa el relato que hace Urania a su familia, a la que no ha visto en más de treinta años, para explicar el porqué de su repentina desaparición, y su negativa a volver, incluso siquiera a comunicarse con ellos, menos aun con su padre. Es, por lo tanto, el momento climático de su historia, una escena clave donde la historia de Trujillo, la forma de su gobierno, el extraño mundo que se generó en torno a él, hasta su asesinato, es resignificado y revalorizado a través de la experiencia de Urania. Se humaniza aun más la historia. Podemos ver en este capítulo, además, una cierta condensación de los estilos narrativos del resto de la novela: el diálogo entre Urania y su familia, con breves interrupciones descriptivas del narrador, para dar paso, intercalándolos, a segmentos narrativos del narrador extradiegético, que va reconstruyendo el momento que Urania relata. En estas narraciones podemos ver también los estilos por los que transita este narrador a lo largo del texto: desde narraciones objetivas ("Le abrió la puerta del auto, la hizo pasar, se sentó a su lado...", 494), intercaladas con segmentos en estilo indirecto libre, adoptando la visión de Urania ("Se acuerda, por ejemplo, que Manuel Alfonso iba de sport - ¿a una fiesta del Generalísimo, de sport?”, 494), o una 
narración en segunda persona, dirigida a esta misma (“Qué vergüenza sentías por ese chofer con gorra, testigo del discurso farsante del embajador", 497). Montaje, diversas voces, tiempos y estilos. Así se va tejiendo este relato humano, ágil, con una carga trágica, inevitable. Del lado de Urania es un discurso seco, duro, y eso le da su potencia, su efecto sobre sus interlocutores (y sobre nosotros lectores). El narrador básico nos ayuda a 'ver' este relato, desde el punto de vista de la niña violada.

La película presenta una escena muy similar a la del libro, pero hay una variación fundamental, pues ahora Agustín Cabral, el padre de Urania, asiste a este relato de la violación / inmolación consentida (por él) de su hija. Esto ya es significativo. El efectismo es evidente. Hay que retroceder un poco y ver cómo está caracterizado este personaje, y el resto de los personajes en general, para entender por qué lo considero antes que nada un recurso efectista, cuando podría darle una sensibilidad mayor a la escena. Urania regresa tras treinta y cinco años (cuatro años menos en la película) y se enfrenta por primera vez al otrora ser más querido de su vida, su padre. Ya no habla, ya no se mueve. La pregunta que siempre se está haciendo su hija, mientras le habla sobre el pasado, es ¿me entenderá?, ¿me reconocerá? En la película esto sucede del mismo modo, solo que la mirada fija y sobreactuadamente triste de su padre sobre ella transforma en estúpido el siquiera preguntárselo. La culpa, la tristeza, el remordimiento se hacen ostensibles desde que el padre aparece en pantalla. La tensión entre el querer decir de Urania y la comprensión / incomprensión del padre se esfuma. Es un monólogo de la hija con su padre, que atiende. Su 'venganza' se consuma, dándole un aura melodramática que en ningún caso tenía la novela. Es por esto que la presencia del padre en la comida, y las constantes apelaciones de su hija mientras narra, no viene sino a reforzar este discurso que de un fuerte valor humano se vuelve meloso, melodramático, $\mathrm{y}$, de acuerdo al estilo genérico, poco convincente como discurso que quiere ser 'real': se convierte en una escena típica y convencionalmente cinematográfica, alejándola de un verosímil que no solo se pretende realista, sino que tienta a lo real.

Este problema de la caracterización de los personajes y del verosímil se concentra en esta escena, por lo decisiva que es (hay secuencias mucho mejor logradas, como la espera y el asesinato de Trujillo), pero que atraviesa toda la realización. Ya vimos el caso del viejo Agustín, convertido en un arquetipo del remordimiento. Pero hay decisiones que a mi juicio son francamente errores, que contribuyen a volver la historia menos verosímil (que debiera ser una preocupación central para esta película) y más 'cinematográfica' (entendiendo 
el adjetivo con una carga negativa: más evidentemente, por su tipificación y esquematización, cine, espectáculo). Veamos, por ejemplo, al personaje central de esta escena, Urania, representada por Isabella Rosellini. Primer problema: el tipo físico, que no se acerca mucho a lo que podría esperarse de Urania. Segundo, un cambio inexplicable. El regreso de Urania, en el filme, se data en 1992, cuatro años antes que la novela. Luego, la protagonista tiene cuarenta y cinco años, edad que por muy bien conservada que esté, no representa la actriz de cincuenta y tres. ¿Por qué no mantener la fecha tal cual la novela? Solo consigue inverosimilizarse más y más ${ }^{30}$. Ocurre también con otros personajes, como el dictador Trujillo, que ni se parece mucho al original, ni logra transmitir la atracción casi divina que le profesaban sus seguidores, ni menos aún el terror paralizante (en la novela se insiste mucho en el efecto de la mirada) que sentían tanto detractores como colaboradores. Por último, para no extenderme más en el tema, un elemento sumamente irritante, sobre todo para un espectador latino. Nuevamente nos encontramos con una especie de convención del cine masivo norteamericano: que los personajes hablen en inglés, pase, el pacto en este caso es aceptar que el inglés representa la lengua nativa de los hablantes, así como en las películas sobre el mundo griego o sobre la época romana se utiliza el inglés como lengua sustituta de la original. Pero cuando los personajes intercambian frases del tipo: "Taxi, please" "Sí, señora" [min. 3:30], o las expresiones de énfasis con un "carajo" al final de una frase en inglés, esa convención se destruye, el inglés ya no sustituye la lengua original, y pareceríamos estar frente a hispanoparlantes que prefieren hablar un mal inglés porque los están grabando para una película. El verosímil se quiebra, la fuerza de lo real se interrumpe: estamos frente a una película, que se autopresenta como un producto de ficción que sigue todos los patrones del cine de masas ${ }^{31}$.

${ }^{30}$ En la novela es tema relevante lo "bien tenida" y lo "igual que está" Urania. De ahí el desajuste con la datación en la película.

${ }^{31}$ Una lamentable tradición del cine norteamericano, hoy mucho más restringida a un cine comercial sin muchas pretensiones. Una tradición donde cualquier actor con un poco de betún hacía de negro, o con un poco menos de latino. Así Anthony Quinn fue árabe, griego, etc., Charlton Heston fue mexicano (fue Moisés), Brando fue Zapata, etc. "Concepción, Chile", decía el intertítulo de un filme reciente, mientras se veían las palmeras, las playas y las guayaberas. En una escala mucho menor, La Fiesta del Chivo lamentablemente se conecta con este tipo de filmes. 
Todos estos elementos se conjuntan en esa escena de la confesión final de Urania: la tendencia hacia el melodrama, la caracterización de los personajes ya mencionados (incluyendo a Trujillo, en el recuerdo), el lenguaje, para construir una ficción que, en tanto mundo posible, pierde todo (o casi todo) marco referencial con el mundo real que le sirve de base, que la novela pretende reescribir, y que forma parte fundamental del efecto estético. El filme puede tener muchos $\log \operatorname{ros}^{32}$, pero me detengo en esta consideración, pues de este modo todo atractivo y fuerza crítica de la novela se pierde, y la historia real se banaliza. Siguiendo la metáfora intertextual, aquí existe diálogo, pero un diálogo interrumpido.

\section{CONCLUSIONES}

En este artículo hemos revisado las tres adaptaciones fundamentales de las novelas de Mario Vargas Llosa. Tres versiones sobre novelas sumamente complejas, que presentan grandes desafíos para su traslado de vehículo sígnico y que, por lo mismo, solo se han revisado de manera parcial (en tanto el análisis pormenorizado requeriría de mucho más espacio), intentando explicar algún aspecto central que sirva al análisis particular de cada texto, pero que en su conjunto den una panorámica general del intercambio de la obra de Vargas Llosa con el cine. Así, el breve análisis de cada adaptación debiera iluminar en alguna dimensión los otros dos textos, desde las dificultades propias de la narrativa de este autor a las potenciales soluciones a estos desafíos para la transposición, con las variantes estéticas que presenta cada director. La detención que le he dado a la técnica (y en parte al estilo) propio de la narración está determinada por las necesidades mismas de estos textos, ya que precisamente a partir de esa misma proliferación discursiva es que ellos despliegan y dan sentido al mundo que contienen, este mundo complejo y contradictorio, inestable y fragmentario, pero profundamente real; es a partir de estas mismas potencias del lenguaje donde estos relatos se enfrentan a la posibilidad de su traslado de medio. La palabra, la imagen y el mundo.

De este modo, el análisis de La ciudad y los perros, aunque parcial, puede dar una idea del esfuerzo consciente de transformación estética que exige

${ }^{32}$ Muchísimo mejor de lo que podría esperarse de un director cuyas películas precedentes son Anaconda y El especialista. 
esta novela (y en menor medida las otras dos) a partir de una técnica que, si bien construye un discurso fuertemente realista, ese mismo realismo exige un uso extremo de los recursos narrativos a través de la palabra. El cineasta debe, entonces, encontrar la forma de hacer de dicho discurso un discurso propio, en un estilo personal, aunque éste sea antitético a la novela; de este modo, las implicancias (estéticas fundamentalmente, pero también éticas, como hemos visto en las tres adaptaciones) de estas transformaciones técnicas variarán de una adaptación a otra, pues dependen fundamentalmente de la propuesta que se construya. Lo mismo ocurre con la dimensión del contenido, o las transformaciones en la diégesis: cada adaptación debe contar su propia historia, inevitablemente violentando el discurso original. Así, en Pantaleón y las visitadoras estas modificaciones en la historia se evidenciaban como una reelaboración genérica, pero que en tanto potencia de manera pertinente los elementos que rescata del original, no aparece en primera instancia como una violencia al texto; en La ciudad y los perros las transformaciones diegéticas las veíamos en la condensación dentro del encierro escolar. Finalmente, en La Fiesta del Chivo veíamos, por una parte, las relaciones extratextuales que establecen el texto y la película (así como la primera de estas novelas con el colegio real, o con la ciudad de Lima) y cuándo dicha relación se puede entender como un elemento central; por otra parte, relacionada con esta idea de 'realidad', nos encontrábamos con la necesidad de dar cuenta de un verosímil que nunca será igual en la pantalla que en el texto, y qué elementos, como la caracterización de personajes, o las convenciones del medio, en un mal trabajo, pueden contribuir a la inverosimilización de la historia.

He intentado dar una mirada conjunta a estas tres novelas no solo por razones de espacio, sino entendiendo que, tal como cada texto original establece un diálogo con la película que lo recupera, así también esta serie de adaptaciones crea un circuito dialógico que contribuye (de mejor o peor manera) a este intercambio entre medios. Cada una de estas películas conversa con las películas que le precedieron y con las películas que vendrán, modificando, una vez más, lo que nosotros podamos decir de estos filmes $\mathrm{y}$, por supuesto, de las novelas mismas.

\section{BIBLIOGRAFÍA}

Andrew, Dudley. “Adaptation”. Film Theory and Criticism: Introductory Readings. Braudy, Leo y Cohen, Marshall (eds.). New York: Oxford University Press, 1999. 452-460. 
Bordwell, David. La narración en el cine de ficción. Barcelona: Paidós, 1996.

Bürger, Peter. Teoría de la vanguardia. Barcelona: Península, 1987.

Casetti, Francesco. Teorías del cine (1945-1990). Madrid: Cátedra, 2005.

Chatman, Seymour. "What Novels Can Do That Films Can't (and Vice Versa)". Film Theory and Criticism: Introductory Readings. Braudy, Leo y Cohen, Marshall (eds.). New York: Oxford University Press, 1999. 435-451.

Gaudreault, André y François Jost. El relato cinematográfico. Ciencia y narratología. Barcelona: Paidós, 1995.

Genette, Gérard. "Discurso del relato”. Figuras III. Barcelona: Lumen, 1989. 77-321.

Goic, Cedomil. Historia de la novela hispanoamericana. Valparaíso: Ediciones Universitarias de Valparaíso, 1972.

Konigsberg, Ira. The Complete Film Dictionary. London: Bloomsbury; New York: New American Library, 1997.

Kristal, Efrain. Tempation of the World. The novels of Mario Vargas Llosa. Vanderbilt University Press, 1998.

Metz, Christian. Ensayos sobre la significación en el cine. Buenos Aires: Tiempo Contemporáneo, 1972.

Mitry, Jean. Estética y psicología del cine. Volumen 1: Las estructuras. Madrid: Siglo XXI Editores, 1998.

La semiología en tela de juicio (cine y lenguaje). Madrid: Akal, 1990.

Perera San Martín, Nicasio. "La ciudad y los perros, génesis de un ciclo novelesco: análisis estilístico”. AIH. Actas VII (1980): 817-824.

Prince, Stephen. "The Discourse of Pictures: Iconicity and Film Studies". Film Theory and Criticism: Introductory Readings. Braudy, Leo y Cohen, Marshall (eds.). New York: Oxford University Press, 1999. 99-117.

Rebolledo, Matías. "Transformaciones de la voz narrativa en la transposición de textos literarios al cine: las resistencias de una narración "silenciosa"'. Tesis de Magíster. Universidad de Chile, 2008.

Russo, Eduardo A. Diccionario de Cine. Buenos Aires: Paidós, 2005.

Tarkovski, Andrei. Esculpir en el tiempo: reflexiones sobre el arte, la estética y la poética del cine. Madrid: RIALP, 1999.

Vargas Llosa, Mario. La ciudad y los perros. 1962. Barcelona: Alfaguara, 2005.

Pantaleón y las Visitadoras. 1973. Barcelona: Seix-Barral, 1976.

La Fiesta del Chivo. Santiago: Alfaguara, 2000.

Wolf, Sergio. Cine / Literatura. Ritos de pasaje. Buenos Aires: Paidós, 2004.

\section{Películas citadas:}

La ciudad y los perros (Francisco J. Lombardi, 1985).

Pantaleón y las Visitadoras (Francisco J. Lombardi, 1999).

La Fiesta del Chivo (Luis Llosa, 2005). 